\section{Inadvertent intraarterial injection of propofol in a patient under general anesthesia}

\author{
Shigeki Mitani ${ }^{1}$, Tadahiko Ishiyama ${ }^{2}$, and \\ Takashi Matsukawa ${ }^{1}$ \\ ${ }^{1}$ Department of Anesthesiology, Faculty of Medicine, University of \\ Yamanashi, Chuo, Japan \\ ${ }^{2}$ Surgical Center, University of Yamanashi Hospital, 1110 Shimoka- \\ to, Chuo 409-3898, Japan
}

To the editor: We describe a case of inadvertent intraarterial injection of propofol in a patient under general anesthesia.

A 62-year-old woman was scheduled for total hip replacement. She had a history of hypertension. In the operating room, a 22-gauge catheter was inserted into a vein in the right forearm. Propofol $10 \mathrm{mg} \cdot \mathrm{ml}^{-1}$ was prepared. Anesthesia was induced with propofol $8 \mathrm{ml}$ and vecuronium $6 \mathrm{mg}$. The patient's lungs were manually ventilated with $5 \%$ sevoflurane in oxygen. Right radial arterial route was established with a 22gauge catheter to observe hemodynamic change caused by endotracheal intubation. Additional propofol $4 \mathrm{ml}$ was administered at the three-way stopcock. Subsequently, her heart rate rose from 110 to 130 beats $\cdot \mathrm{min}^{-1}$. This reaction terminated spontaneously. Then endotracheal intubation was performed. About $30 \mathrm{~s}$ later, we noticed propofol left in the arterial route. Inadvertent intraarterial injection of propofol was recognized and approximately $1.5 \mathrm{ml}$ of propofol was drawn from the arterial route; therefore, $2.5 \mathrm{ml}$ of propofol would have been injected into the radial artery. After the arterial injection of propofol, the waveform of arterial pressure and oxygen saturation measured by pulse oximeter at the injected site did not change significantly. In addition, her right hand was warm and her color did not alter. Anesthesia proceeded and the operation was performed. She was extubated and did not complain of pain or show hyperesthesia or functional deficit. Eight hours after the inadvertent injection of propofol, the patient complained of an unpleasant sensation in the right metacarpophalangeal joints; the sensation disappeared $1 \mathrm{~h}$ later without any specific treatment.

In the awake phase, severe pain is one of the most common symptoms of the intraarterial injection of propofol [1]. However, in the present case, the patient was anesthetized and she could not complain of severe pain. Instead, her heart rate increased immediately. Our result conflicts with Vohra's report [2] showing that the intraarterial injection of propofol did not trigger any change of hemodynamic parameters under sedation. However, because the intraarterial injection of propofol causes severe pain, an increase in heart rate following the injection of propofol under sedation or general anesthesia would be one of the important symptoms of intraarterial injection.

In our case, the patient had an unpleasant sensation in the right metacarpophalangeal joints postoperatively. Propofol has been reported to produce vascular permeability change [3]. One case report mentioned that residual cutaneous hyperemia lasted for 12 days [4]. Furthermore, there is a possibility that intraarterial propofol attenuates capillary blood flow by particulate embolization or by physical interaction with blood components [5]. There may have been transient vascular hyperpermeability or a decrease in capillary blood flow in the present patient.

Two laboratory studies [5,6] have shown that intraarterial propofol did not influence vasoactivity or vascular myogenic activity, and it was not toxic to the vessel wall. Intraarterial propofol has not been reported to cause irreversible sequelae, even when $8 \mathrm{ml}$ of propofol was injected [1]. In contrast, the intraarterial injection of thiopental is known to cause endothelial cell destruction and necrosis, and urgent management of vasodilation or anticoagulation is required. Propofol may be a safer induction agent compared with thiopental. Nevertheless, it is important to prevent the intraarterial injection of propofol. After experiencing this incident, we have changed the color of the three-way stopcock to red, and the syringe has been connected to the three-way stopcock to avoid drug injection to the arterial route.

\section{References}

1. Holly HS, Cuthrell L. Intraarterial injection of propofol. Anesthesiology. 1990;73:183-4.

2. Vohra SB. Inadvertent intra-arterial infusion of propofol. $\mathrm{Br} \mathbf{J}$ Int Care. 1995;5:306-7.

3. Chen YS, Chen KH, Liu CC, Lee CT, Yang CH, Chuang KC, Lin CR. Propofol-induced vascular permeability change is related to the nitric oxide signaling pathway and occludin phosphorylation. J Biomed Sci. 2007;14:629-36.

4. Ang BL. Prolonged cutaneous sequlae after intra-arterial injection of propofol. Singapore Med J. 1998;39:124-6.

5. MacPherson RD, Rasiah RL, McLeod LJ. Intraarterial propofol is not directly toxic to vascular endothelium. Anesthesiology. 1992;76:967-71.

6. Babacan A, Akacabay M, Uluglu O, Ozakocak I, Karadenizl Y. The histopathological comparison of the result of the intra-arterial injections of propofol and thiopentone in rabbits. Mater Med Pol. 1992;24:41-4.

Address correspondence to: T. Ishiyama

Received: September 2, 2008 / Accepted: November 20, 2008 